\title{
A SWIMMING POOL-RELATED OUTBREAK OF PHARYNGOCONJUNCTIVAL FEVER IN CHILDREN DUE TO ADENOVIRUS TyPE 4, GiPUZKOA, SPAin, 2008
}

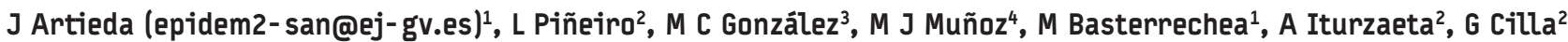 \\ 1. Epidemiology Unit, Basque Governement's Health Department, Gipuzkoa, Spain \\ 2. Microbiology Service, Hospital Donostia, San Sebastián, Spain \\ 3. Public Health Center of Tolosa, Spain \\ 4. Basque Public Health Service-Osakidetza, Center of the Goierri area, Spain
}

\begin{abstract}
An outbreak of pharyngoconjunctival fever affecting 59 children was detected in a municipality of northern Spain in July 2008. The outbreak was related to insufficient doses of water disinfectant in the municipal swimming pool. Adenovirus was detected in the pharyngeal swabs of five of six affected children and the four strains that were sequenced were all Adenovirus type 4.

\section{Introduction}

Pharyngoconjunctival fever can be caused by both picornaviruses and adenoviruses. The latter are divided into six species $(A-F)$ with 51 known serotypes to date [1]. Humans are the reservoir for this virus and although frequently asymptomatic, adenovirus infections can affect the upper and lower respiratory tract and the eye and can also cause gastroenteritis and cystitis. In addition, adenoviruses are excreted in the respiratory and intestinal mucosa, in the latter sometimes for prolonged periods of time. The incubation time varies from two to 14 days, and transmission occurs through respiratory secretions, person-to-person contact, aerosolised viruses and fomites, as well as the faecal-oral route.
\end{abstract}

Although the first recorded outbreaks of pharyngoconjunctival fever associated with adenovirus transmission in a swimming pool were reported more than 50 years ago [2], this type of outbreak has been reported only rarely in the past few decades [3-5]. On 3 July 2008, the Epidemiological Surveillance Service of Gipuzkoa was notified of an unusually high number of children with fever, pharyngitis and/or conjunctivitis, who had consulted the paediatrician at the health centre of a municipality in the Goierri region. The present study describes the epidemiological, environmental and virological investigations that were performed to study this outbreak, and the control measures established.

\section{Methods}

Cases were defined as all individuals under the age of 15 years consulting the health centre of the affected town between 15 June and 11 August with conjunctivitis and/or pharyngitis with enlarged cervical lymph nodes. According to the census from 2006, the town had 9,141 inhabitants of whom 1,347 were under 15 yearsold. The possible occurrence of cases of pharyngoconjunctival fever in the neighbouring towns and a referral hospital was monitored. Affected patients were interviewed in order to record the following variables: place of residence, age, sex, date of symptom onset, symptoms, presence of complications, swimming pool use and other potential exposures. For each clinical picture, (pharyngoconjunctivitis, pharyngitis without conjunctivitis, and conjunctivitis without pharyngitis), two cases were studied in order to identify viral aetiology, using pharyngeal swabs with viral transport medium (ViralPack, Biomedics, Spain). For adenovirus detection, a real-time polymerase chain reaction (PCR) method was used that amplified a fragment of the hexon gene [6], and the amplicons obtained were sequenced to characterise the adenovirus type. The $\mathrm{pH}$ value and the concentration of disinfectant in the water of the four basins of the public swimming pool were determined (Test Cloro and $\mathrm{pH}$ 1.11174.0001, Merck, Germany), the automatic pH regulation and disinfectant dosing pump system was inspected and the incident log book was reviewed. Disinfection was performed through bromination in the small inner children's pool and through chlorination in the remaining pools.

\section{Results}

Between 16 June and 11 August, 59 children were diagnosed with pharyngoconjunctival fever and met the case definition. Forty-three of the children (73\%) had recently used the municipal swimming pool, which was considered the source of infection (primary cases). Fifteen (25\%) of the children had been in close contact with a primary case (secondary cases). The very first case that occurred had not visited the swimming pool and was therefore considered sporadic. The epidemic curve confirmed an outbreak with an epidemic pattern characterised by an accumulation of primary cases, consistent with the hypothesis of a persistent common source, and more isolated secondary cases, resulting from person-to-person transmission mainly in a family environment (Figure).

All affected infants and children lived in the area where the swimming pool is situated. They were 34 (58\%) boys and 25 (42\%) girls. Ten percent of affected individuals were under the age of one year, $29 \%$ were between one and four years-old, $59 \%$ between five and 13 years-old and one case was 14 years-old (2\%). It must be noted that the case definition only included children under the age of 15 years; an estimation of the secondary attack rate among older children and adults in the families or contacts was 
therefore not possible. Forty-three percent had fever, pharyngitis and conjunctivitis, $29 \%$ had fever and pharyngitis and $28 \%$ had conjunctivitis with or without fever. All affected children were diagnosed by pediatricians and three required a consultation with an ophthalmologist due to keratoconjunctivitis. There were no hospitalisations and all cases received symptomatic treatment. Adenovirus was detected in five of the six pharyngeal swabs collected (two children with pharyngitis, one with conjunctivitis and two with pharyngitis and conjunctivitis), and the virus was identified as Adenovirus type 4 in the four amplicons that were sequenced.

After the swimming pool opened (on 7 June) for the summer season, there were numerous electrical system failures causing intermittent failure of the water circulation and bromine dosing pumps. The disinfectant concentrations registered on 3 July (the day the outbreak was reported) were insufficient in the small children's pool $(0.45 \mathrm{mg} / \mathrm{l}$ of total bromine) and were adequate in the remaining pools. On the same day, swimming in the small pool was forbidden. Once the disinfection system was repaired and normal disinfection concentrations (bromine and $\mathrm{pH}$ ) were confirmed, swimming was again permitted.

\section{Discussion}

Swimming pool-related outbreaks of viral infection are highly uncommon. The most frequently involved viruses are adenovirus, norovirus, hepatitis A virus and echovirus, in this order [7]. The outbreak reported in the present study was due to an adenovirus type 4 most probably transmitted through the water of the inner children's pool. The abrupt onset of this outbreak generated a certain alarm in the health sector and in the population, but after the system breakdown was repaired and control measures were established, the incidence of infection decreased sharply. Due to logistic problems, no water samples were taken from the swimming pool for virological analysis, which would have allowed the aetiology of the outbreak to be unequivocally confirmed.

\section{F I G U R E}

Cases of pharyngoconjunctival fever, by date of disease onset, Gipuzkoa, Spain, June-August ${ }^{\mathrm{a}} \mathbf{2 0 0 8}^{\star}(\mathrm{n}=59)$

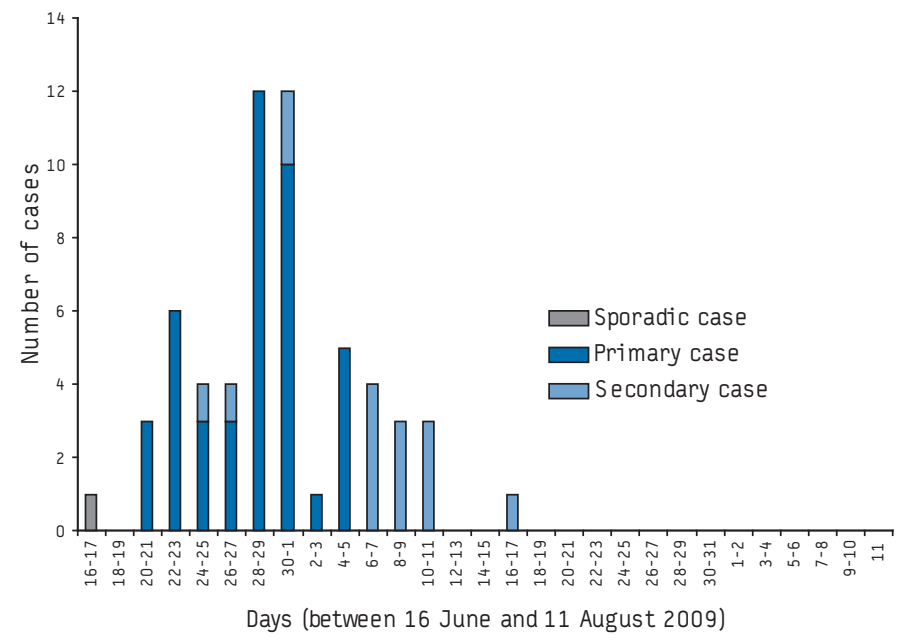

${ }^{a}$ Active surveillance was ongoing until 11 August
Adenoviruses are non-enveloped viruses, unusually resistant to physical and chemical agents, which gives them prolonged survival capacity [1]. Recently, these viruses have been observed to be prevalent in rivers, coastal water, swimming pools and water supplies worldwide [8,9]. Adenoviruses have also been detected in swimming pool water in the context of outbreaks of pharyngoconjunctival fever $[3,4,10]$. Transmission of this virus can occur both through intake of swimming pool water or through direct contact between the water and the conjunctival mucosa or upper respiratory tract [9]. The clinical presentation of cases in this outbreak was consistent with pharyngoconjunctival fever, as reported in other swimming pool-related outbreaks of non-enteric adenovirus infection [2-5,10-12]. Adenovirus type 3 has been most frequently found in these outbreaks $[2,3,5,11,12]$, and to a lesser extent, type $7[13,14]$ and type 4 [10]. Adenovirus type 4, the only member of human adenovirus species $\mathrm{E}$, is one of the major causes of adenoviral conjunctivitis and the type considered to be responsible for the outbreak reported here. Clinical manifestation of this virus type varies, ranging from pharyngoconjunctival fever to keratoconjunctivitis, unlike conjunctivitis caused by serotypes 3 and 7 , which tend to be milder [15].

It is obvious that the electrical problems at the swimming pool must have affected the disinfectant regulation system severely. However, the record books do not report any disinfection problem. We consider it disputable whether the measurements between the start of the electrical problems and the beginning of our in situ study were performed correctly. We strongly believe that strict adherance to the existing regulation would have avoided the outbreak.

The reports published to date would seem to indicate that swimming pool-related outbreaks of adenovirus infection have become exceptional in the last few decades. However, the outbreak reported in the present study reveals that these infections continue to pose a risk to swimming pool users when recommended control guidelines are not strictly observed. Adequate standards of hygiene and disinfection must be maintained in these installations to prevent transmission of adenoviruses and other microorganisms, and early investigations could decrease the number of cases

*Erratum: The date in the figure title, erroneously published as June-August 2009, was corrected to June-August 2008. This change was made on 2 March 2009.

\section{References}

1. Echavarría M. Adenoviruses. In: Zuckerman AJ, Banatvala JE, Pattison JR, Griffiths PD, Schoub BD, editors. Principles and Practice of Clinical Virology. 5th edition. Chichester, England: John Wiley \& Dons, Ltd.; 2004. p. 343-60.

2. Ormsby HL, Aitchison WS. The role of the swimming pool in the transmission of pharyngeal-conjunctival fever. Can Med Assoc J. 1955;73(11):864-6.

3. Centers for Disease Control (CDC). Outbreak of pharyngoconjunctival fever at a summer camp - North Carolina, 1991. MMWR Morb Mortal Wkly Rep. 1992;41(19):342-4. Available from: http://www.cdc.gov/mmwr/preview/ mmwrhtml/00016704.htm

4. Papapetropoulou M, Vantarakis AC. Detection of adenovirus outbreak at a municipal swimming pool by nested PCR amplification. J Infect. 1998;36(1):101-

5. Harley D, Harrower B, Lyon M, Dick A. A primary school outbreak of pharyngoconjunctival fever caused by adenovirus type 3. Commun Dis Intell. 2001;25(1):9-12.

6. Xu W, McDonough MC, Erdman DD. Species-specific identification of human adenoviruses by a multiplex PCR assay. J Clin Microbiol. 2000;38(11):4114-20.

7. World Health Organization. Guidelines for safe recreational water environments. Volume 2: Swimming pools and similar environments. Geneva, Switzerland: World Health Organization; 2006. Chapter 3: Microbial hazards. p. 26-59. 
8. Jiang SC. Human adenoviruses in water: occurrence and health implications: a critical review. Environ Sci Technol. 2006;40(23):7132-40.

9. van Heerden J, Ehlers MM, Grabow WO. Detection and risk assessment of adenoviruses in swimming pool water. J Appl Microbiol. 2005;99(5):1256-64.

10. D’Angelo LJ, Hierholzer JC, Keenlyside RA, Anderson LJ, Martone WJ. Pharyngoconjunctival fever caused by adenovirus type 4: report of a swimming pool-related outbreak with recovery of virus from pool water. J Infect Dis. 1979;140(1):42-7.

11. Martone WJ, Hierholzer JC, Keenlyside RA, Fraser DW, D’Angelo LJ, Winkler WG. An outbreak of adenovirus type 3 disease at a private recreation center swimming pool. Am J Epidemiol. 1980;111(2):229-37.

12. Foy HM, Cooney MK, Hatlen JB. Adenovirus type 3 epidemic associated with intermittent chlorination of a swimming pool. Arch Environ Health. 1968;17(5):795-802.

13. Turner M, Istre GR, Beauchamp H, Baum M, Arnold S. Community outbreak of adenovirus type $7 \mathrm{a}$ infections associated with a swimming pool. South Med J. 1987;80(6):712-5.

14. Caldwell GG, Lindsey NJ, Wulff H, Donnelly DD, Bohl FN. Epidemic of adenovirus type 7 acute conjunctivitis in swimmers. Am J Epidemiol. 1974;99(3):230-4.

15. Aoki K, Tagawa Y. A twenty-one year surveillance of adenoviral conjunctivitis in Sapporo, Japan. Int Ophthalmol Clin. 2002;42(1):49-54.

This article was published on 26 February 2009

Citation style for this article: Artieda J, Piñeiro L, González MC, Muñoz MJ, Basterrechea M, Iturzaeta A, Cilla G. A swimming pool-related outbreak of pharyngoconjunctival fever in children due to adenovirus type 4, Gipuzkoa, Spain, 2008. Euro Surveill. 2009;14(8):pii=19125. Available online: http://www.eurosurveillance.org/ViewArticle. aspx?ArticleId $=19125$ 